\section{P159 PRELIMINARY EXPERIENCE OF A TAILORED ILD PULMONARY REHABILITATION PROGRAM AND INSPIRATORY MUSCLE TRAINING DELIVERED IN A HOSPICE AND HOME SETTING}

${ }^{1} \mathrm{M}$ AlQuaimi, ${ }^{2} \mathrm{~L}$ McNeillie, ${ }^{2} \mathrm{C}$ Donaldson, ${ }^{3} \mathrm{~J}$ Harper, ${ }^{2} \mathrm{~J}$ Hartley, ${ }^{4} \mathrm{~S}$ Cassidy, ${ }^{3} \mathrm{AM}$ Bourke, ${ }^{4} \mathrm{~J}$ Simpson, ${ }^{4} \mathrm{C}$ Ward, ${ }^{2}$ I Forrest. ${ }^{1}$ Imam Abdulrahman Bin Faisal University, Dammam, Saudi Arabia; ${ }^{2}$ The Newcastle upon Tyne Hospitals NHS Foundation Trust, Newcastle upon Tyne, UK; ${ }^{3}$ Marie Curie Hospice, Newcastle upon Tyne, UK; ${ }^{4}$ Newcastle University, Newcastle upon Tyne, UK

\subsection{6/thoraxjnl-2017-210983.301}

Background Dysponea, muscle wasting, and fatigue are common manifestations in interstitial lung disease (ILD). Pulmonary rehabilitation programmes (PRP) aim to improve symptoms and quality of life in ILD but research is very limited about the role and feasibility of inspiratory muscle training (IMT) in PRP.

Methods Six patients with a mixed disciplinary team diagnosis of ILD (5 males, median age 80 range $67-85$ ) participated in a tailored PRP either in an IMT $(n=3)$ or control group $(n=3)$. PRP involved three days of exercises, one conducted in a hospice day therapy unit and two at home. The PRP session involved aerobic, strength, and stretching exercises with integrated education and relaxation sessions. Both groups received the same PRP, supplemented in the IMT group by the use of a POWERbreathe Medic plus respiratory muscle trainer. The trainer use consisted of 30 breaths twice daily with personalised resistance levels of 40\% Maximal Inspiratory Pressure (MIP), which was measured and adjusted weekly. ILD outcome measures were recorded before and after PRP.

\begin{tabular}{|c|c|c|c|c|c|}
\hline & & IMT & & Control & \\
\hline Outcomes & $\begin{array}{l}\text { Normal } \\
\text { Values }\end{array}$ & $\begin{array}{l}\text { Before } \\
\text { PRP } \\
\text { (mean } \\
\pm S D \text { ) }\end{array}$ & $\begin{array}{l}\text { After } \\
\text { PRP } \\
\text { (mean } \\
\pm \text { SD) }\end{array}$ & $\begin{array}{l}\text { Before } \\
\text { PRP } \\
\text { (mean } \\
\pm S D \text { ) }\end{array}$ & $\begin{array}{l}\text { After PRP } \\
\text { (mean } \\
\pm S D \text { ) }\end{array}$ \\
\hline K-Bild & 105 & $70.0+15$ & $72 \pm 5$ & $68 \pm 14$ & $69 \pm 12$ \\
\hline Depression & $0-7$ & $4 \pm 2.64$ & $\begin{array}{l}4.67 \\
\pm 0.577\end{array}$ & $6.33 \pm 5.77$ & $5.33 \pm 6.65$ \\
\hline Anxiety & $0-7$ & $6 \pm 1.73$ & $\begin{array}{l}6.33 \\
\pm 0.577\end{array}$ & $5.0 \pm 2.646$ & $4.33 \pm 3.22$ \\
\hline FSS & 9 & $46 \pm 20$ & $41 \pm 7$ & $45.0 \pm 12$ & $45 \pm 15$ \\
\hline $\begin{array}{l}\text { Visual analogue Fatigue } \\
\text { scale }\end{array}$ & 10 & $2.67 \pm 2.08$ & $6.5 \pm 0.71$ & $\begin{array}{l}3.33 \\
\pm 0.577\end{array}$ & $4.67 \pm 3.51$ \\
\hline MIP (mmHg) & $(n=65$ to 75$)$ & $43 \pm 12.1$ & $\begin{array}{l}61.44 \\
\pm 18.3\end{array}$ & $\begin{array}{l}66.23 \\
\pm 38.7\end{array}$ & $\begin{array}{l}52.16 \\
\pm 35.23\end{array}$ \\
\hline FVC (L) & & $3.13 \pm 0.33$ & $2.5 \pm 0.52$ & $2.45 \pm 0.78$ & $2.3 \pm 0.79$ \\
\hline $\begin{array}{l}\text { Quadriceps strength } \\
\text { (Newtons) }\end{array}$ & & $289 \pm 67$ & $286 \pm 6$ & $328 \pm 164$ & $294 \pm 121$ \\
\hline 6MWT (M) & & $380 \pm 49$ & $425 \pm 21$ & $355 \pm 207$ & $351 \pm 224$ \\
\hline
\end{tabular}

Results All patients completed the PRP with adherence of $\geq 80 \%$ for the full program. There were no major complications or adverse events and patients reported liking and enjoying the PRP and environmental setting. Table 1 report the PRP outcomes. Description: there was a considerable prevalence of baseline limitation in term of depression, anxiety, fatigue severity scale (FSS), forced vital capacity (FVC) and six-minute walk test (6MWT). These limitations were maintained after PRP and there was a reduction in FVC in both groups, consistent with disease progression. In the IMT group there was a trend for an improvement in MIP, 6MWT, FSS, and visual analogue fatigue scale and a maintenance of quadriceps strength when compared with the control group.

Conclusion We believe this is the first description of a successful pilot of bespoke ILD PRP in a hospice and home setting. The PRP was acceptable and appreciated by both patients and healthcare professionals. IMT during PRP for ILD in a hospice setting is feasible and longitudinal measurements of fatigue, 6MWT, and MIP were practicable end points that warrant further study.

\section{P160 MORTALITY FROM IDIOPATHIC PULMONARY FIBROSIS IN ENGLAND AND WALES BY BIRTH COHORT}

${ }^{1} \mathrm{C}$ Reynolds, ${ }^{2} \mathrm{C}$ Barber, ${ }^{1} \mathrm{P}$ Cullinan. ${ }^{1}$ Department of Occupational and Environmental Medicine, National Heart and Lung Institute, London, UK; ${ }^{2}$ Centre for Workplace Health, University of Sheffield, Sheffield, UK

\subsection{6/thoraxjnl-2017-210983.302}

Introduction and Objectives The incidence of idiopathic pulmonary fibrosis (IPF) has been increasing at a rate of $5 \%$ per annum since 2000. By definition, the diagnosis of IPF is not made in the presence of an identifiable cause. However, the distribution of the disease in the population (more common in men, manual workers, and those living in more industrial areas of the country) suggests a causal contribution from an occupational or environmental source. This would be expected to produce a cohort effect. Our aim was to examine trends in IPF mortality data for evidence of such an effect.

Methods Age and sex stratified mortality data for IPF were obtained for England and Wales from the Office of National Statistics for the period 1974-2012. Data were age-

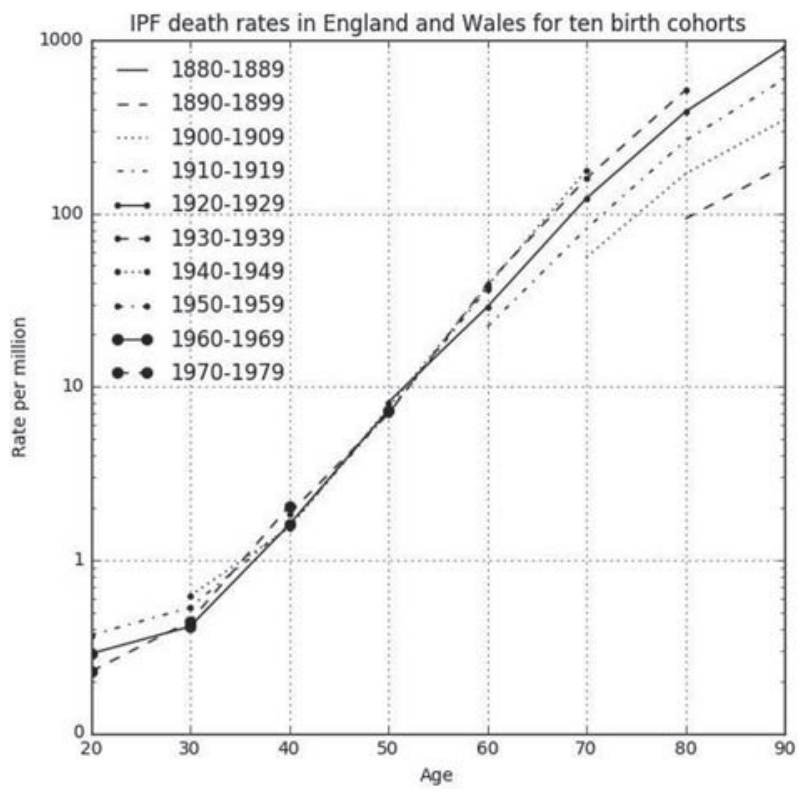

Abstract P160 Figure 1 
standardised and visualised using the Python Pandas data analysis library and matplotlib.

Results There is evidence of a cohort effect with age-specific IPF death rates increasing in successive cohorts, most clearly seen from age 60. Overall rates were higher for men but there were not marked sex differences in cohort mortality trends (data not shown).

Conclusions The birth cohort effect we observed is consistent with a proportion of IPF cases being due to an occupational or environmental exposure with latency and further research is needed.

\section{Early detection and screening in TB}

\section{P161 TUBERCULOSIS CONTACT SCREENING: WILL THE 2016 GUIDELINES LEAD TO MISSED DIAGNOSES?}

J Prynn, ECJ Bailey, M Darmalingam. Barts Health NHS Trust, London, UK

\subsection{6/thoraxjnl-2017-210983.303}

Background UK TB contact screening guidelines changed in $2016,{ }^{1}$ requiring screening only of contacts of patients with potentially transmissible disease, specifically pulmonary or laryngeal TB. TB contacts and the index case are likely to have had similar TB exposure, and it is possible that contacts who have not been directly infected by the index case will be missed using the new screening guidelines.

Aims and Objectives This study aimed to evaluate whether all cases of TB diagnosed through contact tracing in 2012 at a University Hospital would have been identified using the new screening guidelines.

Methods Case notes of all patients contact screened for TB aged 16 and over in 2012 were examined. Data were collected on the diagnosis of the patient screened (negative, latent, or active TB) and the site of $\mathrm{TB}$ of the index case.

Results Of the 445 screened, $394(88.5 \%)$ were negative for $\mathrm{TB}, 44(9.9 \%)$ had latent $\mathrm{TB}$, and $7(1.6 \%)$ had active $\mathrm{TB}$. For $19.6 \%$ of those with latent or active $\mathrm{TB}$ diagnoses, the $\mathrm{TB}$ site in the index case was neither pulmonary nor laryngeal.

Conclusion By restricting contact screening of this 2012 cohort to those with pulmonary or laryngeal TB contact, 10 (19.6\%) cases of TB would potentially have been missed. As these missed contacts and the TB index case may have had exposure to $\mathrm{TB}$ from the same, albeit unknown, person with a transmissible form of $\mathrm{TB}$, the only way to identify these cases is with a broad screening approach. While the current guidelines are in place, this study highlights the importance of assessing the need for contact screening based on the individual clinical picture in each identified case of TB.

\section{REFERENCE}

1. National Institute of Clinical Excellence. Tuberculosis Guidance: Update Information 2016.

\section{P162 ANALYSIS OF AND LESSONS FROM THE MULTIPLE SCREENING EPISODES IN UK'S TUBERCULOSIS PRE- ENTRY SCREENING PROGRAMME: OCTOBER 2005 TO DECEMBER 2016}

MC Muzyamba, R Harris, D Zenner. Public Health England, London, UK

\subsection{6/thoraxjnl-2017-210983.304}

Background The UK has been carrying out pre-entry tuberculosis (TB) screening for all long term migration visa applicants in 15 pilot countries since October 2005. Screening was subsequently rolled out to visa applicants in 101 high TB incidence $(\geq 40 / 100 \quad 000$ population $)$ countries. Individuals screened free of pulmonary TB are issued with medical clearance certificates valid for 3 and 6 months for those with or without close contact with a TB case, respectively. Consequently, individuals who travelled to the UK on multiple occasions need rescreening once their certificates have expired. Screening identifies prevalent $\mathrm{TB}$ cases among migrants thereby reducing incidence and onward transmission in the UK.

Methods Our study used a cohort of migrants from 40 high incidence countries screened for TB pre-entry by the International Organisation for Migration between October 2005 and December 2016. All applicants screening prior to certificate expiry were excluded. Odds ratios (ORs) and relative risk ratios (RRRs) were estimated using logistic and multinomial logistic regression, respectively, to identify factors associated with multiple screening.

Results The cohort consisted of 855591 migrants screened for pulmonary TB. $729232(85.0 \%)$ were screened once but $126358(15.0 \%)$ were screened $\geq 2$ times. After adjusting for age and sex, the factors associated with being screened $\geq 2$ times included being diagnosed with TB (OR 3.40; 95\% CI 2.99-3.85), close contact with TB (OR 1.29 95\% CI 1.181.40 ) and certain visa types (Settlement: 1.95 ; 95\% CI $1.93-$ 1.97, baseline Student visa). Applicants from the Indian subcontinent were more likely to screen multiple times than other regions. RRRs for individual categories using multinomial logistic regression were similar to overall ORs. Multiple screenings were also associated with increased TB detection. Conclusions Being diagnosed with $\mathrm{TB}$, being a close contact of a TB case and those applying for settlements visa were more likely to be screened multiple times. This information could be used for targeted follow up of individuals likely to screen multiple times and determine their risk of TB.

\section{P163 AN AUDIT INTO THE COMPLETENESS OF LATENT TUBERCULOSIS SCREENING IN THE GASTROINTESTINAL DEPARTMENT, PRIOR TO PATIENTS STARTING ANTI- TNF-A THERAPY}

SM Meghji. University of Southampton, Southampton, UK

10.1136/thoraxjnl-2017-210983.305 